\title{
EL ARTE DEL BORDADO EN NAVARRA EN LOS SIGLOS XVI Y XVII: ANDRÉS DE SALINAS
}

\author{
POR \\ ALICIA ANDUEZA PÉREZ \\ Departamento de Historia del Arte. CSIC
}

\begin{abstract}
Dada su condición de arte decorativa, y su consideración como una labor meramente artesanal, la atención que se le ha prestado al bordado es escasa. Por suerte, en los últimos años estamos asistiendo a un resurgir de los estudios sobre el tema. Este artículo, siguiendo estas nuevas tendencias, pretende esclarecer algunos aspectos sobre esta actividad en la Navarra de los siglos XVI y XVII.

Palabras clave: Bordado. Navarra. Andrés de Salinas

Given its classification as a decorative art, and its perception as mere artisanal work, scarce attention has been given to embroidery. Nevertheless, fortunately, in recent years there has been a resurgence of studies on this theme. This article, following these new trends, attempts to clarify certain aspects of this activity in the Navarre region during the sixteenth and seventeenth centuries.
\end{abstract}

Key words: Embroidery. Navarre. Andrés de Salinas.

El bordado es un arte legendario y las noticias sobre su existencia se remontan a fechas muy antiguas. A pesar de esto, y de la riqueza y esplendor que esta actividad logró en la Península, la atención que se le ha prestado es escasa. En el caso de Navarra, el arte del bordado, siguiendo la sintonía general, se caracteriza por la falta de estudios sobre el tema, a pesar de la amplia cantidad de documentación que se encuentra en los archivos navarros consultados '. En las primeras décadas del siglo pasado, Biurrun y Sotil nos da alguna información sobre bordadores y obras bordadas en Navarra, pero ésta es escasa y en muchos casos, confusa ${ }^{2}$. Sí contamos con dos trabajos más actuales, que aunque no se centran de manera específica en el análisis del bordado, arrojan noticias de gran interés para su estudio. Uno es el escrito que Ricardo Fernández Gracia realizó sobre la sacristía de la Catedral de Pamplona y en el cual analiza los ornamentos que en ella se conservan, y el segundo es un estudio que sobre los contratos de aprendizaje en diversos oficios llevó a cabo María Victoria Hernández Dettoma, y en el cual

\footnotetext{
Archivo General de Navarra (A.G.N.) y el Archivo Diocesano de Pamplona (A.D. de Pamplona).

${ }^{2}$ Biurrun y Sotil, T., La escultura religiosa y Bellas Artes en Navarra durante la época del Renacimiento, Pamplona, 1935 .
}

AEA, LXXVI, 2003, 303, pp. 287 a 300 
incluye a los bordadores ${ }^{3}$. Además de estas obras, contamos con referencias a ornamentos bordados en el Catálogo Monumental de Navarra, y con un artículo sobre el bordador navarro Antonio de Estanga en la revista Estudios de Ciencias Sociales ${ }^{4}$.

Por tanto, el objetivo de este trabajo es aportar, a través del análisis del bordador Andrés de Salinas, algunos datos sobre la situación del bordado en Navarra, teniendo siempre en mente que el panorama es mucho más amplio, y esto sólo supone un pequeño acercamiento. Dejando a un lado el bordado popular, nos ocuparemos específicamente del bordado erudito, y concretamente de las vestiduras sagradas, ocupación principal de los bordadores de estos siglos.

El deseo es aún mayor. Estamos acostumbrados a denominar arte a una pintura, a un edificio o a una escultura singular. Pero hay viejos usos y oficios que contribuyeron en un pasado al embellecimiento y adorno de casas, templos y vidas, y que deben tenerse en su justa consideración. Uno de estos viejos usos es el bordado, un auténtico arte ornamental, que merece también ocupar una parcela más destacada en la historia del arte.

\section{Panorama general}

El siglo XVI, junto con el siglo XV y XVII en menor medida, constituyen la «edad de oro» del bordado español. Es también el siglo xvi el periodo en el que el bordado erudito aplicado a las piezas litúrgicas alcanza su máximo desarrollo, produciéndose un perfeccionamiento y un dominio de las diferentes técnicas.

El panorama navarro se supone similar al general de España, siendo también el siglo XVI, sobre todo su segunda mitad, y el siglo XvII el periodo en que mayor auge logró el bordado en dicha comunidad. Las noticias sobre bordadores en Navarra son muy abundantes durante las últimas décadas del siglo XVI y primera mitad del siglo xvII, percibiéndose a partir de esta fecha un gran vacío en la documentación, probablemente producido por una cierta decadencia en el oficio. Se nos escapan las razones que propiciaron este declive, pero quizá tenga algo que ver la importante crisis textil que sufrió en el siglo xvII Zaragoza, ya que esta ciudad aragonesa debió ser lugar de abastecimiento de ricas telas para los bordadores navarros, como demuestra el testimonio del bordador Juan González de Ezquerecoechea que dice que fue a Zaragoza en 1628 a «cobrar ciertos maravedies que se le debian como a traer sedas y otros recados» 5 .

Son muchos los bordadores establecidos en Pamplona que encontramos en la documentación, siendo las décadas de transición del siglo XVI al XVII las más prolíficas. Antonio de Estanga, Miguel de Azcárate, Miguel Ibañez, Andres de Salinas, Pedro de Unzueta o Agustín de Villava, son buena muestra de ello. Como queda patente el oficio profesional del bordado estaba en manos de artífices masculinos, siendo muy pocas las bordadoras de las que tenemos noticia. En Navarra en el siglo Xvil contamos con el ejemplo de Graciosa de los Ángeles, una monja del convento de las carmelitas descalzas de San José de Pamplona que dirigió las obras de bordadura de un pontifical para Fitero ${ }^{6}$. Seguramente el bordado se debió ejercer, aunque

\footnotetext{
${ }^{3}$ Fernández Gracia, R., «La sacristía en la catedral de Pamplona. Uso y función. Los ornamentos», Príncipe de Viana, 1999, pp. 349-381; Hernández Dettoma, M.V., «El contrato de aprendizaje artístico: Pintores, plateros, bordadores», Príncipe de Viana, 1989, pp. 493-517.

${ }^{4}$ García Gaínza, M. ${ }^{\text {a }}$., y otros, Catálogo Monumental de Navarra, Institución Príncipe de Viana, Gobierno de Navarra, Departamento de Educación y Cultura, Arzobispado de Pamplona, Universidad de Navarra, Pamplona, 1980; Bermejo Barasoain, A., «Antonio Eztanga, bordador», Estudios de Ciencias Sociales, 8, UNED, Pamplona, 1995.

5 A.D. de Pamplona, 1629, C/321-N².

${ }^{6}$ Fernández Gracia, R., Op. cit., p. 365.
}

AEA, LXXVI, 2003, 303, pp. 287 a 300 
no de manera profesional, en los conventos femeninos, dato que vemos constatado, por ejemplo, en la provincia de Ávila ${ }^{7}$. Y ya en el siglo xviII y xIX, con la apertura de escuelas de encajes y bordados, la incorporación de la mujer a este oficio se hizo efectiva ${ }^{8}$.

No se han hallado noticias sobre la existencia del gremio ni sobre sus ordenanzas, lo cual no es un caso singular en España, puesto que la misma situación se da en otras provincias españolas, como Granada o Murcia, donde no se constata la existencia del gremio de bordadores ni de una cofradía propia ${ }^{9}$. Pero sí hay lugares donde se conservan las ordenanzas y ciertas noticias de corporativismo gremial, como Sevilla o Barcelona, lo cual deja abierto el panorama para que se puedan conservar y hallar en otras provincias ${ }^{10}$. En el caso de Navarra, Hernández Dettoma, basándose en el testamento de Agustín de Villava, dice que los bordadores tenían como patrón a San Fermín al que veneraban en la iglesia de San Lorenzo ${ }^{11}$.

Los bordadores de los que tenemos noticia, llevaron a cabo numerosos encargos para diversas parroquias navarras, pero intuimos que su actividad traspasó en ocasiones las fronteras del reino, ya que hay noticias de que algunos se ausentaron en ocasiones de Navarra, posiblemente para llevar a cabo otros encargos, de los que por ahora, no tenemos constancia. Un ejemplo es la declaración transcrita anteriormente de Juan González de Ezquerecoechea que se trasladó a Zaragoza, entre otras cosas, para cobrar cierta cantidad que se le debía. Sobre este mismo bordador, Andrés de Salinas, que también en 1616 se ausentó del reino ${ }^{12}$, dice que no tenía casa fija en la ciudad y solía ir a trabajar a Castilla y otras partes ${ }^{13}$. También Carlos de Urroz, bordador que fue aprendiz de Andrés de Salinas, se ausentó mientras éste le tenía a su cargo y «estuvo en la ciudad de Çaragoça ganando salario de oficial» ${ }^{14}$.

Asimismo, también en Navarra se encargaron obras a artistas foráneos, sobre todo de las provincias cercanas, como Zaragoza o la Rioja, con las que las relaciones artísticas fueron en todos los géneros muy fluidas. En la parroquia de Santa María de Viana se conserva un terno realizado por el bordador riojano Hernando del Busto entre 1549 y 1558, y otros dos ternos rojos bordados en oro por el maestro, también riojano, Pedro del Bosque ${ }^{15}$. Asimismo, José Gualba, destacado maestro zaragozano realizó un terno para Estella ${ }^{16}$.

Estos ejemplos pretenden ser una muestra de cómo se pudo desarrollar la actividad del bordado en Navarra, y como ésta no se mantuvo cerrada en sus fronteras, tanto por trabajos de nuestros bordadores fuera como por las obras de artistas foráneos en nuestra comunidad. A esto hay que sumar las obras importadas que encontramos en Navarra de los puntos más importantes del bordado español, como Barcelona, Granada o Toledo, de las cuales conservamos importantes ejemplares en la Catedral de Pamplona ${ }^{17}$.

Los dos grandes clientes de piezas bordadas fueron la iglesia y las cofradías. Respecto al trabajo de los bordadores para estas últimas, un ejemplo es el estandarte para la Cofradía del Rosario de Arroniz, de quince varas de damasco blanco, que realizó en la década de los treinta

\footnotetext{
7 Vázquez García, F., «Aportaciones documentales para el estudio de las obras de cantería, carpintería, orfebrería, bordados y escritura en Ávila durante la segunda mitad del siglo xvi», Cuadernos Abulenses, 7, Enero-Junio 1997, p. 38.

${ }^{8}$ Véase López Castán, A., «Las escuelas femeninas de encajes en el Madrid ilustrado», en La mujer en el arte español, VII Jornadas de Arte, Departamento de Historia del Arte «Diego Velázquez», Centro de Estudios Históricos, CSIC, 1997, pp. 265-270.

${ }^{9}$ Pérez Sánchez, M., El arte del bordado y del tejido en Murcia. Siglos XVI- XIX., Universidad de Murcia, 1999, p. 54.

${ }^{10}$ Turmo, I., Bordados y bordadores sevillanos, Laboratorio de Arte, Universidad de Sevilla, Sevilla, 1955, pp. 25-26.

"Hernández Dettoma, M.V., Op. cit., p. 511.

12 A.G.N. Tribunales Reales. Procesos. 1616. 041539.

13 A.D. de Pamplona, $1629, \mathrm{C} / 321-\mathrm{N}^{\circ} 2$.

14 A.G.N. Tribunales Reales.1595. C/2-N ${ }^{\circ} 16$.

${ }^{15}$ García Gaínza, Ma C., y otros, Op. cit., Merindad de Estella, II**, p. 585.

${ }^{16}$ Ágreda Pino, A.M., «Aportaciones al estudio del patrimonio artístico textil en Aragón. Los ornamentos de la Catedral de San Salvador de Zaragoza», Artigrama, 13, 1999, p. 384.

${ }^{17}$ Fernández Gracia, R., Op. cit., p. 366.
} 
del siglo xviI, Pedro de Unzueta, uno de los bordadores navarros más destacados del segundo tercio del siglo XVII ${ }^{18}$. Por su parte, la iglesia era consumidora de indumentaria clerical y paños sagrados, para su uso y adorno. Es característico del panorama navarro la pobreza de ornamentos en las iglesias y la gran necesidad que había de ellos. Esta situación fue evidente incluso en la primera de las iglesias navarras, la Catedral de Pamplona ${ }^{19}$. Partiendo de esta necesidad se entiende que durante los siglos XVI y xvII, la mayoría de las iglesias navarras contrataran obras de bordadura y que pocas fueran las visitas pastorales en las cuáles no se mandaran hacer ornamentos para el servicio del culto divino. Un buen ejemplo de esto es la licencia que, durante el episcopado de Fray Prudencio de Sandoval, se dio a Andrés de Salinas y Martín de Urroz para llevar a cabo todos los ornamentos que se habían mandado realizar en la visita pastoral a los arciprestazgos de la Valdorva y Valdelónguida:

«Don Fray Prudencio de Sandoval, obispo del dicho obispado del Consejo de su M a . Por quanto en la vissita q el licenciado Pedro de anines nuestro vissitador a hecho de los Arciprestados de la Valdorba y Valdelonguida, a allado $q$ en todas sus iglessias para su adorno y servicio del Culto divino ay precissa necessidad de frontales, casullas, ternos y otros ornamentos y obras de vordadura. Teniendo consideracion q Andres de Salinas y Martin de Urroz vordadores vecinos desta ciudad son perssonas q con toda comodidad y brevedad possible haran y acavaran bien y perfectamente las obras aquí escritas les damos licencia paraque las hagan, es afan en el lugar de Esquiroz un frontal de Damasco blanco, en Galar se adrese la casulla de Damasco blanco y se haga una estola para ella y otra negra y un Palio y Muceta, en Esparca dos frontales de tela para los Altares colaterales y Un Palio y muceta de tela,, En Salinas una cassulla de Damasco blanco y una capa de Dos colores blanca y negra y de la colorada de paño se haga un frontal,, (...) En tiebas dos dalmáticas de Damasco blanco para la casulla,, (...) En Usun una capa negra de Difuntos,, en Domeño una cassulla de Chamelote colorado,,(...) En Artajo tres frontales uno de damasco blanco y otro de chamelote colorado y otro negro con cruz en medio...» ${ }^{20}$.

La lista de pueblos y ornamentos correspondientes es larga. A los citados les siguen otros, Ochagavía, Rípodas, Ezcaroz, Ustarroz... Por medio de este documento podemos constatar esa necesidad y pobreza de ornamentos que caracterizaba a las iglesias navarras, y a su vez podemos entrever la posición destacada que nuestro bordador, Andrés de Salinas, ocupaba en el arte del bordado navarro, al concederle el obispo Sandoval licencia para tan dilatada cantidad de obras.

Observamos también de esta manera el relevante papel que la iglesia concedía a las vestiduras y paños sagrados, dada la extraordinaria importancia que adquiere la liturgia tras el Concilio de Trento. Estos ropajes bordados eran uno de los vehículos al servicio de la iglesia más adecuados para mostrar la fastuosidad del ceremonial litúrgico, y darle ese toque final de esplendor. El papel de la indumentaria religiosa era exponer la solemnidad y santidad de las personas que la portaban, y por ende, de la institución que representaban. Buena muestra de ello son las palabras que encontramos en las Constituciones Sinodales de 1591: «... para los religiosos y religiosas, están dedicadas ciertas vestiduras, que significan la santidad y pureza de su estado...» ${ }^{21}$. De ahí, que tengamos que ver estas piezas, no sólo como objetos de arte en sí mismos, sino como un medio de expresión más al servicio de la iglesia católica.

En las Constituciones Sinodales del Obispo Bernardo de Rojas y Sandoval, que acabamos de citar, encontramos pocas menciones a los bordados, pero las que hay nos dan cierta idea de la normativa existente respecto a estas obras. En el libro tercero, capítulo quinto, se decreta lo que se ha de hacer con las vestimentas que se consumen con el tiempo: «Mucho cuydado se

\footnotetext{
18 A.D. de Pamplona, 1634, C/552-N³.

19 Fernández Gracia, R., Op. cit., p. 363.

20 A.D. de Pamplona, 1629, C/321-N².

${ }^{21}$ Rojas y Sandoval, B., Constituciones Synodales del obispado de Pamplona,1591, p. 119.
}

$A E A$, LXXVI, 2003, 303, pp. 287 a 300 
debe tener por los Curas, y capellanes de la conservacion, y buen tratamiento de los ornamentos de sus Iglesias. Y quando estuvieren tan consumidos, que no se puedan dellos aprovechar para algun servicio, y ornato de la yglesia, en tal caso no se deven convertir en uso alguno profano, mas antes, con licencia de nuestro visitador, se deven quemar y echar las cenizas por la pila baptismal abaxo» ${ }^{22}$.

Así vemos, además de la importancia concedida a la conservación de estas piezas, una de las razones por las cuales la mayoría de estas vestiduras no se han conservado. Otra causa, también documentada, era el acto frecuente de fundir los ornamentos ricamente adornados pero deteriorados por su uso, para reaprovechar el oro y la plata.

Pero la alusión más interesante que hallamos en estas Constituciones, es la referente a «lo que se ha de guardar en las obras de bordados» (Libro tercero, capítulo séptimo) y que reza así : «Item- por la experiencia Nos consta el grande gasto, que las iglesias padecen en los bordados, que se hazen en los ornamentos, no pudiéndose averiguar con puntualidad el valor, y que en ellos se gasta más de lo que conviene, y después de hechos los bordados, se echan a perder con el mal trato. Y queriendo prevenir a todo S.S.A. mandamos, que de aquí en adelante no se hagan en las iglesias ornamentos bordados, sino que se gasten telas de oro y plata y sedas con franjas, pasamanos: salvo si alguno por su devoción quisiere de su hazienda dar algún ornamento bordado a la yglesia. Y sea lo mismo en mangas y frontales, salvo en la yglesia mayor de Pamplona» ${ }^{23}$.

Esta medida de no utilizar bordados en los ornamentos viene dada por el gran endeudamiento con el que se cargaban la mayoría de las iglesias navarras, fruto de la contratación de estas piezas, y que a su vez les llevaba a verse envueltas en pleitos inacabables con los bordadores por retraso en los pagos.

Sin embargo, no fue Pamplona el único lugar donde se dio esta situación, sino que también en otros obispados peninsulares se dictaron medidas para limitar el importante gasto y endeudamiento que producía la contratación de ornamentos bordados. Así, por ejemplo, en las Constituciones Sinodales del obispado de Sigüenza de 1655, Título XXIV, capítulo 3 se dice lo siguiente: «Una de las mayores perdiciones que hemos hallado en las Iglesias, es averse dexado vencer los Provisores fácilmente de los ruegos, y importunaciones de los maestros de obras, y de los favores de que se han valido para que les diesen, y encargasen obras, no solo no necesarias, sino antes superfluas, y escusadas, como son, las que se han hecho de costosisimos bordados, y otras de plata de muchos marcos (...) todo lo cual no ha servido, sino de consumir los alcançes que tenían a favor las iglesias, y dexarlas empenadas para muchos años (...). Por tanto mandamos, que de aquí adelante no se hagan bordados en las iglesias, sino todas las casullas, y demás ornamentos, con solo un galón de plata, y de oro que divida las zenefas $(\ldots){ }^{24}$.

Pero estas medidas no sabemos hasta que punto tuvieron repercusión, puesto que las iglesias siguieron requiriendo en muchos casos vestiduras y paños bordados. Lo que sí se puede observar es cómo en muchas ocasiones en lugar de hacer obras nuevas, se manda reparar las ya existentes o se reutilizan las cenefas bordadas de piezas deterioradas aplicándolas a nuevos tejidos, lo cual constituía un ahorro importante para las parroquias. Esta es la razón de que a veces encontremos piezas con franjas o cenefas de fechas anteriores:

\footnotetext{
22 Ibíd., p. 121.

23 Ibíd., p. 127.

${ }^{24}$ Cita que se toma de Ágreda Pino, A.M.,«El bordado en Zaragoza en el siglo xviII, entre el esplendor y la crisis: Apuntes para el estudio de la consideración del arte del bordado en la Edad Moderna», Artigrama, 14, Departamento de $\mathrm{H}^{\mathrm{a}}$ del Arte, Universidad de Zaragoza, Zaragoza, 1999, p. 308.
} 
Andrés de Salinas: vida y obra

La trayectoria profesional de Andrés de Agriano y Salinas ${ }^{25}$, bordador vecino de Pamplona, transcurrió principalmente en el primer tercio del siglo xvII, ya que su primer trabajo documentado data de 1595. Nació alrededor del año 1565, y respecto a su aprendizaje las noticias son inexistentes. No es aventurado pensar que pudo formarse en el taller de Juan y Miguel de Sarasa, padre e hijo, los dos, renombrados bordadores, dado que Salinas estaba casado con una de las hijas de Juan de Sarasa. Sea como fuere, para la década de los ochenta ya usaba del oficio de bordador. Trabajó casi hasta la fecha de su muerte, 1632, pero su trabajo durante sus últimos años de vida debió disminuir ya que estaba aquejado de enfermedad en una pierna. Durante todos esos años su trayectoria profesional fue prolífica, y una de las más intensas y sobresalientes del panorama del bordado en Navarra.

Casó con Graciana de Sarasa, con la que tuvo siete hijos, tres varones y cuatro féminas. Su hijo, Juan de Agriano y Salinas, casado con Graciosa de Izu y padre de dos hijas, Francisca y Graciosa, continuó el oficio aprendido de su padre, llegando a ser también un destacado bordador. Sus hijas, María y Josepha, casarán respectivamente, con Andrés de Voca, músico ministril de la Catedral de Pamplona, y con Pedro de Lecumberri, que también seguirá los pasos de su suegro dedicándose al bordado. Es por tanto el caso de Andrés de Salinas buen ejemplo de la endogamia familiar que se daba en todos los oficios artísticos. Recordemos a los Berruguete, a los Siloé y a Pacheco y Velázquez, o ya dentro de los bordadores a la familia de los Álvarez en Zaragoza ${ }^{26}$. Pasando el oficio de padres a hijos o a otros miembros de la familia, se facilitaba el aprendizaje del oficio y se aseguraba la continuidad del taller formado.

Podemos precisar donde vivió, ya que tenemos noticia de una casa en la que vivieron su hija María y su marido Andrés de Voca, y que antes habitó él ${ }^{27}$. Este inmueble que constaba de dos viviendas se encontraba en el barrio de la Catedral, frontera por un lado a la del destacado ensamblador Domingo de Bidarte, que sabemos estaba ubicada en la subida a la $\mathrm{Seo}^{28}$, y por el otro a la calle Navarrería. Debió nuestro bordador tener relación con Bidarte, puesto que éste actúa como testigo en varias de sus escrituras. No es extraño encontrar a Andrés de Salinas viviendo cerca de la Catedral, ya que es lógico pensar que los bordadores se asentaran cerca del templo catedralicio o de las parroquias principales de la ciudad, ya que éstas constituían su principal cliente. No sabemos con certeza la ubicación de la vivienda de otros bordadores, pero no es una hipótesis aventurada, ya que este hecho se documenta en otros lugares de España, como Murcia o Jaén ${ }^{29}$.

Tenía abierto taller en Pamplona, con aprendices y oficiales a su cargo. Él mismo nos lo dice «.. tiene obrador abierto y oficiales peritos, y él mismo con su persona trabaja y da la traza y forma de las obras que se hacen en su casa» ${ }^{30}$.

Respecto a los oficiales, sabemos que el sueldo de un oficial debía rondar los cuatro reales al día, aunque estas cantidades debieron oscilar ${ }^{31}$. En Sevilla, por ejemplo, un oficial cobraba cinco reales de jornal, a finales del siglo xvi y nueve o diez reales a mediados del XVII ${ }^{32}$. Sus condiciones en el taller eran mejores que las de los aprendices, ya que disfrutaban a la hora de

\footnotetext{
${ }^{25}$ En la documentación aparece como Andrés de Agriano y Salinas, o solamente Andrés de Salinas.

${ }_{26}$ Ágreda Pino, A.M. «El arte del bordado en Zaragoza en el siglo xvi: Agustín Álvarez», Artigrama, 1994-95, 11, Departamento de $\mathrm{H}^{\mathrm{a}}$ del Arte, Universidad de Zaragoza, Zaragoza, pp. 339-406.

27 A.G.N. Tribunales Reales. Procesos. 1616. 041539.

${ }^{28}$ García Gaínza, MaC., La escultura romanista en Navarra, Pamplona, 1969, p. 121.

29 Pérez Sánchez, M., Op. cit., p. 23.

${ }^{30}$ A.D. de Pamplona, 1629, C/321- N².

31 A.G.N. Tribunales Reales. Procesos. 1595, C/2, No16.

32 Turmo, I., Op. cit., p. 27.
}

$A E A$, LXXVI, 2003, 303, pp. 287 a 300 
comer de plato separado y de vino y pan, a diferencia de los aprendices, que comían en el mismo plato y sólo se les daba agua ${ }^{33}$.

En cuanto al aprendizaje del oficio de bordador son más los aspectos que conocemos. Andrés de Salinas tuvo como aprendices a Carlos de Urroz, con quien firmó contrato de aprendizaje el 1 de agosto de 1592, y a Joan de Bereterechea en 1605. También debió aprender con él el oficio su hijo Juan de Agriano, que a su vez tuvo como aprendiz a Joan de Salzedo, en $1627^{34}$. Su yerno, Pedro de Lecumberri, también estuvo vinculado a su taller, ya que además de la relación de parentesco que lo supone, lo encontramos trabajando muy próximamente con él, figurando como oficial. Pero fueron más los que pasaron por su taller, algunos de los cuales encontraremos después como distinguidos bordadores. En 1661, su sobrino Pedro de Agriano, declara que Juan de Santos, Juan de Arratia y Pedro de Unzueta, fueron criados de Andrés de Salinas. Así bien, el último bordador de renombre que encontramos en Pamplona en el siglo xviI, Agustín de Villava, también pasó por el taller de dicho maestro bordador ${ }^{35}$.

Tal y como nos dice Hernández Dettoma, el padre era el que usualmente se encargaba de efectuar el contrato, aunque podía acudir personalmente al notario y otorgar poder a otras personas para que lo realizaran en su nombre ${ }^{36}$. En el caso de Carlos de Urroz es su padre, Juan de Urroz, sastre de la ciudad de Pamplona, el responsable de perpetrar el contrato. El dicho Carlos de Urroz comenzó el aprendizaje con la edad de 15 años, y el periodo de duración que se estableció fue de 6 años, que empezó a partir de la fecha de firma del contrato, aunque debía ser costumbre que los aprendices sirvieran unos meses antes de hacer la escritura para ver si se convenían y agradaban mutuamente ${ }^{37}$. Joan de Bereterechea entró como aprendiz a los 16 años y la duración del contrato se estableció también en 6 años. El periodo de aprendizaje establecido dentro de los bordadores debió variar entre dos y siete años, siendo, como hemos visto, cinco y seis años lo más usual ${ }^{38}$.

Las obligaciones del maestro consistían en dar de comer, vestir y calzar al aprendiz estando sano y «también estando enfermo quando la emfermedad no pasara de quinze dias». Debía «... enseñarle el dicho su arte y oficio de bordador en lo que a el fuere posible, tratandolo vien». $\mathrm{Al}$ final del aprendizaje el maestro tenía que darle «el bestido de paño nuevo (...) con medias griguesco jubon y sombrero como es costumbre darse» ${ }^{39}$. Obligándose a todo esto el maestro bordador con su persona y bienes muebles y raíces.

El aprendiz se ocupaba tanto de lo referente al oficio como de los asuntos domésticos, actuando también de criado. El padre, o el que en su lugar efectuara el contrato, se obligaba a darle parte del vestuario y todo lo necesario durante sus enfermedades. Así Juan de Urroz se comprometió a dar a su hijo «... camisas en los dichos seis años... un ferreruelo ${ }^{40}$ nuevo con unas medias nuebas y le drecara y reparara el bestido viejo que tiene». En el caso de que el aprendiz se ausentara antes de cumplir los años estipulados el padre le debía volver a traer, y si no podía, debía pagar al bordador medio real por cada día de los que estuvo el aprendiz a su servicio. En el caso de Andrés de Salinas y Carlos de Urroz, el motivo del pleito fue éste. El aprendiz se ausentó a los tres años del aprendizaje y según las acusaciones del maestro estuvo trabajando con otros maestros y ganando jornal en Zaragoza. La otra

${ }^{33}$ A.G.N. Tribunales Reales. Procesos, 1633, C/2- Nº.

${ }^{34}$ A.G.N.Tribunales Reales.Procesos,1595,C/2-Nº16; Hernández Dettoma, M.V., Op. cit., p. 511.

${ }_{35}$ A.D. de Pamplona, 1629, C/321-N ${ }^{\circ}$ 2. A.G.N. Tribunales Reales. 1661. 152031.

${ }^{36}$ Hernández Dettoma, M.V., Op. cit., p. 511.

37 A.G.N. Tribunales Reales. Procesos, 1595, C/2- Nº16.

${ }^{38}$ Hernández Dettoma, M.V., Op. cit., p. 512.

${ }_{39}$ A.G.N. Tribunales Reales. Procesos, 1595, C/2- Nº 16.

${ }^{40}$ Se trata de una capa larga, con cuello y sin capillo. 
parte se defendía acusando a Andrés de Salinas de haber dado maltrato y mala vida al muchacho ${ }^{41}$.

Uno de los aspectos más interesantes en el estudio del aprendizaje y desarrollo del oficio de bordador, es su relación con el dibujo. Es posible que algunos de los maestros bordadores, además de dominar las técnicas del bordado, los tipos de tejido y de hilo, conocieran el arte del dibujo. Una muestra de ello es un dibujo de una casulla de la segunda mitad del siglo XVIII firmado por el bordador José Velaz, que se encuentra en el Archivo Municipal de Pamplona y que es uno de los escasos dibujos de bordadores que se conservan en España ${ }^{42}$.

Por todo esto, es probable que el dibujo formara parte del aprendizaje del oficio de bordador, aunque los datos con los que contamos sean escasos como para dilucidar claramente el papel que éste debió ocupar. Las únicas referencias que tenemos en Navarra son el contrato de Hernando de Echasarri con el maestro Santos Sarmiento, donde se estipula que en los días de fiestas le deje al dicho Hernando hacer dibujos y ejercicios del dicho oficio, y la escritura de Pedro de Gainza, donde se especifica que Agustín de Villava le debía enseñar el dicho oficio y el dibujo ${ }^{43}$.

Además no sólo eran los bordadores los que proporcionaban los modelos de las piezas bordadas, sino que muchas veces eran los pintores los que se ocupaban de estos dibujos preparatorios. Palomino al explicar la manera en la que se llevaba a cabo el bordado alude a que «... el perfecto modo es tener a la vista lo pintado o iluminado de mano de un pintor lo que se ha de ejecutar» ${ }^{44}$. Así vemos que los artistas más célebres no desdeñaron hacer modelos para bordados. Lefebure nos cuenta que Rafael se ocupó muchas veces en bordados, conservándose en París un medallón bordado en el Museo de Cluny, cuyo dibujo hizo él por encargo del rey Francisco ${ }^{45}$.

En España también tenemos alguna noticia. Por ejemplo, muchos de los pintores que estuvieron trabajando en la fábrica de El Escorial realizaron dibujos y modelos para los bordados, contándose entre éstos personajes tan ilustres como Navarrete el Mudo, Bartolomé Carducho o Miguel Barroso ${ }^{46}$. Antonio Gómez de los Ríos, bordador de cámara de Fernando VI en un memorial que presentó al Rey sobre las piezas de un pontifical que había elaborado, dijo haberlas hecho todas bordadas «costeando los dibujos que son de varios autores, así como Rubens, Rafael, Luis Velázquez, Salimeno y otros muchos» ${ }^{47}$. En Sevilla, el pintor Luis de Vargas hizo el dibujo para que Gabriel de Morejón bordara la entrada de Jesús en Jerusalén, en un capillo, y en Granada también contamos con algunos ejemplos ${ }^{48}$.

Un ejemplo navarro de este papel de los pintores en la realización de modelos y dibujos preparatorios para el bordado, es que los ornamentos realizados por Pedro de Unzueta para la parroquia de Echarri, fueron dibujados por Andrés de las Heras, pintor de Asiaín ${ }^{49}$.

En lo que se refiere a la trayectoria profesional de Andrés de Salinas es, como hemos aludido antes, una de las más abundantes y destacadas del panorama del bordado navarro. Él mismo nos lo dice, es él el «... que ha hecho las obras más grandiosas que se ofrecen en este obis-

\footnotetext{
${ }^{41}$ A.G.N. Tribunales Reales. Procesos.1595, C/2- No16.

${ }^{42}$ García Gaínza, M ${ }^{\mathrm{a}}$ C., y otros, Op. cit., Merindad de Pamplona, V***, p. 187.

${ }^{43}$ Hernández Dettoma, M.V., Op. cit., p. 511.

${ }_{44}$ Palomino de Castro y Velasco, A., El museo pictórico y escala óptica, 1714, Prólogo de Ceán y Bermúdez, Madrid, 1947, p. 78.

${ }^{45}$ Lefebure, E., El bordado y los encajes, La España Editorial, Madrid, p. 113.

46 Villanueva, A.P., Los ornamentos sagrados en España, Ed. Labor, Barcelona, 1935, p. 231; Junquera de Vega, P., «El obrador de bordados de El Escorial», El Escorial 1563-1963, II, p. 579.

${ }^{47}$ Niño, F., «Una obra del bordador de cámara Antonio Gómez de los Ríos», Archivo Español de Arte, 14, 1940-41, p.

${ }^{48}$ Eisman Lasaga, C., Op. cit., p. 44.

49 Hernández Dettoma, M.V., Op. cit., p. 510.
} 311. 
pado...» ${ }^{50}$. Y aunque pueda verse esta declaración como una falta de modestia, o quizás una exageración en pos de la victoria en un pleito, lo cierto es que la documentación demuestra la gran cantidad de obras que realizó, las numerosas iglesias navarras con las que contrató y la alta estima en la que se tenía su trabajo en la Pamplona de la época.

La primera obra de la que tenemos noticia data de 1595 , cuando contrata un conjunto de ornamentos para la iglesia de Olazagutía, consistente en una capa, una casulla, un frontal, todo ello de damasco blanco con cenefas y guarniciones de raso carmesí, y otra casulla de alguna telilla blanca. Sumaban estas vestiduras la cantidad de 85 ducados, que debían ser pagados al bordador en dos plazos. 52 ducados para el 1 de noviembre de 1595 y 33 ducados para el 31 de enero de 1596. Así mismo, Andrés de Salinas, se obligaba a presentar el frontal y la casulla para el día de Navidad y el resto de las obras para la fiesta de Pascua ${ }^{51}$.

Ésta era la manera en la que se realizaban los contratos de obras de bordadura. En la mayoría de los casos, tras el mandato de visita, se pedía licencia para la realización de las obras. Una vez concedida se disponía a establecer el contrato o escritura de convenios. En estos contratos se describía detalladamente las obras a ejecutar, atendiendo al tipo de tejido que se debía usar, a cómo debía ser la decoración o la técnica que se debía utilizar. Se fijaba en principio el precio aproximado y la forma de pago, así como el plazo máximo de entrega del trabajo. La iglesia o parte contratante se obligaba, con sus rentas y bienes, a pagar las obras en los plazos estimados, y el bordador, se comprometía a realizar la obra perfectamente para la fecha estipulada. Una vez terminado el bordado, se procedía a la tasación de la obra, que era realizada por dos maestros bordadores, uno por cada parte contratante.

A principios del siglo xvir encontramos a Andrés de Salinas disputando junto a Miguel Ibañez, la confección de diversos ornamentos para la iglesia de Valtierra que se habían mandado realizar en la última visita. Esto era algo normal, no sólo entre los bordadores, sino en todos los oficios, el artista que mejor oferta propusiera en cuanto a calidad, tiempo y precio, era el que se adjudicaba la obra. Las piezas en cuestión eran, entre otras, un terno compuesto de capa, casulla, dos dalmáticas, con sus estolas y manípulos, paño para el facistol, y un frontal, todo ello de damasco violado con cenefas de raso y damasco carmesí, «... sin ninguna bordadura...» y diez casullas de chamelote de los colores que la iglesia prefiriese ${ }^{52}$. Es un claro ejemplo de la medida expuesta en las Constituciones Sinodales y de cómo se prescindía muchas veces de los bordados por el encarecimiento que suponían de la obra.

Entre la documentación del pleito se haya la memoria de la costa del dicho terno, frontal y casullas, presentada por Andrés de Salinas, y que es de gran interés ya que nos permite ver los materiales que eran necesarios para la realización de una obra, en este caso de un terno y diez casullas, así como la cantidad y precio del tejido que se necesitaba para cada pieza, y el coste que ésta tenía en su totalidad. Para la confección del terno se precisaban en total 30 varas de damasco violado, unos 25 metros, adjudicándose «para la capa ocho baras, para la casulla coatro baras $\mathrm{y} \mathrm{m}^{\mathrm{a}}$, para las dos dalmaticas diez baras con estolas y manipulos, para el facistol dos baras y $\mathrm{m}^{\mathrm{a}}$, para el frontal cinco baras si es algo crecido el altar». Para las cenefas de damasco carmesí o raso se requerían 13 varas y media. El precio del damasco aparece establecido en 32 reales la vara, con lo que si las cenefas se hacían de damasco, el precio ascendía a 1392 reales. Si las cenefas eran de raso carmesí, la iglesia se podía ahorrar 94 reales, ya que la vara de raso se sitúa en unos 25 reales. Andrés de Salinas también cita 41 varas y media de bocaci ${ }^{53}$ entre fino, aproximadamente 34 metros, para hacer los forros y los de las cenefas dobles. El precio

\footnotetext{
50 A.D. de Pamplona, 1629, C/321- $\mathrm{N}^{\circ} 2$.

51 A.D. de Pamplona, 1597, C/153- $\mathrm{N}^{\circ} 8$.

52 A.D. de Pamplona, 1604, C/209-N 2.

53 Tela de hilo engomado, de varios colores, para forros.
} 
del bocaci era de a 3 reales la vara, sumando en total 124 reales y medio, y apunta que «si el bocaci fuere de Paris se ahorran 2 reales en cada vara». A esto se añaden las 27 onzas de «sedas para franjas y coser con borlas en el capillo y collares», que a 6 reales la onza, montaban 162 reales, y la hechura de todo ello, estimada en 10 ducados. Por tanto, el precio del terno completo alcanzaba los 1788 reales, aproximadamente unos 162 ducados ${ }^{54}$.

En lo que se refiere a las casullas, si estas eran de chamelote de Lebante ${ }^{55}$, cada una de ellas se estimaba en 122 reales, montando las diez los 1220 reales. Si estas se hacían de lilla ${ }^{56}$ se ahorraba 6 ducados en cada casulla, unos 660 reales en total.

Si se hacían las casullas de lilla, las cenefas del terno de raso y se utilizaba el bocaci de París, el terno y las diez casullas venían a costar 2313 reales, más o menos, unos 210 ducados. Aunque Salinas aconseja a la iglesia hacer las casullas de chamelote porque «... las lillas duran poco...» y usar el bocaci más grueso, poniendo sólo las cenefas del terno violado de raso. Acaba la memoria poniéndose como plazo para entregar las obras un mes ${ }^{57}$.

Miguel Ibañez, bordador que trabaja en la mismas fechas que Andrés de Salinas, rebajó la oferta de éste, tanto en tiempo como en precio. Propuso acabar la obra en 20 días y utilizar dos varas de damasco menos que el dicho Salinas, por un ducado más barato, disminuyendo también el valor en cada casulla. Al final, Salinas decidió renunciar a la obra argumentando «... no ser hombre que en semejantes obras ni otras pretende ganar con tratos ylicitos...» y porque «... en lo que toca al hacer de la dicha obra, por no ser de bordadura, ni poder mostrar el suplicante lo que sabe hacer no la pretende ni quiere...» ${ }^{58}$.

Los materiales que empleaban los bordadores eran proporcionados por la iglesia, aunque en ocasiones los mismos artistas ponían además de la mano de obra, el material. Frecuente debía ser que la iglesia aportara la tela y los artistas los hilos ${ }^{59}$. Las parroquias adquirían estos materiales de los mercaderes, a los que hay que tener muy en cuenta pues juegan un importante papel dentro del mundo del bordado. En el caso de las vestiduras para la parroquia de Valtierra, los materiales fueron proporcionados por un mercader de Tudela, Agustín Nabarro, que se los fió a la iglesia por unos meses, a cambio de 60 ducados ${ }^{60}$. También hay que destacar las intensas relaciones existentes entre los mercaderes y bordadores, que en muchas ocasiones actúan como cesionarios de estos últimos, seguramente como forma de pago de las deudas que contraían con ellos por la adquisición de tejidos e hilos. En el caso de Andrés de Salinas, le encontramos relacionado con un mercader francés, Antonio de Pegenaut, que aparece como su cesionario, con derecho a cobrar parte del pago de diversas obras de bordadura que Salinas realizó ${ }^{61}$. Pero éste no es un caso aislado, ni sólo aplicable a este bordador, sino que es algo muy frecuente en la mayoría de bordadores navarros. Así, el mercader Esteban de Oberón aparece como cesionario de Antonio de Estanga, Martín de Ardánaz del bordador Martín de Urroz, y Juan de Bereterreche y Luis de Viscarret, mercaderes pamploneses, como cesionarios de Miguel de Azcárate, otro de los más señalados bordadores navarros de la primera mitad del siglo XvII ${ }^{62}$.

\footnotetext{
${ }^{54}$ Hay que tener en cuenta que el precio de los diferentes tejidos variaba según la época y el lugar. Como comparación, podemos apuntar que unos cincuenta años atrás en Sigüenza, la vara de damasco costaba 550 maravedíes, unos 16 reales; la vara de bocaci se estimaba en 6 reales, y la onza de seda a 3 reales y 3/4. Peces Rota, F-G., «El bordado, en la Catedral de Sigüenza, al servicio del arte religioso», Memoria Ecclesiae, 16, 2000, p. 164.

55 Debía costar aproximadamente a 11 reales la vara. El chamelote o camelote es el tejido de pelo de camello, fuerte e impermeable. Es muy frecuente el de aguas.

${ }^{56}$ Cierto género de tejido o tela de lana, de varios colores, que se usaba para vestido y otras cosas. Se llama así por tener su origen en Lila, ciudad de Flandes.

57 A.D. de Pamplona, 1604, C/209- $\mathrm{N}^{\circ} 2$.

58 A.D. de Pamplona, 1604, C/209-N² 2.

59 Vázquez García, F., Op. cit., p. 37.

${ }^{60}$ A.D. de Pamplona, 1604, C/209- $\mathrm{N}^{\circ} 2$.

61 A.D. de Pamplona, 1633, C/542- $\mathrm{N}^{\circ} 29$.

${ }^{62}$ A.D. de Pamplona, 1591, C/88- $\mathrm{N}^{\circ} 17 ; 1605, \mathrm{C} / 230-\mathrm{N}^{\circ} 14 ; 1618, \mathrm{C} / 277-\mathrm{N}^{\circ} 9 ; 1619, \mathrm{C} / 279-\mathrm{N}^{\circ} 7$.
}

AEA, LXXVI, 2003, 303, pp. 287 a 300 
En febrero de 1603 Andrés de Salinas contrata con la iglesia de Beriain la realización de dos casullas, tres frontales y una bursa ${ }^{63}$. Entrega una casulla de telilla y la dicha bursa, recibiendo a cambio ocho ducados, y comprometiéndose a ejecutar las obras restantes ${ }^{64}$.

Hacia 1604, bajo el obispado de Don Mateo de Burgos, llevó a cabo obras de gran importancia para la iglesia de Santa María de Monreal. En la tasación de las obras vemos descritos los ornamentos que Salinas ejecutó. El conjunto consistía en un terno de damasco blanco con su capa, casulla, dalmáticas, paño de facistol y su frontal, donde todas las guarniciones de las piezas estaban «... bordadas con oro fino y sedas», y que de acuerdo al mandato de visita debía tener las cenefas bordadas a lo romano y sin figuras excepto en el capillo de la capa, donde debía de ponerse la imagen de la vocación de la iglesia; otro terno violado, con capa, casulla y dalmáticas, esta vez de chamelote; otra casulla y dos dalmáticas de damasco blanco; una muceta de damasco carmesí bordado a la redonda, y en el medio dos ángeles con un cáliz ${ }^{65}$; unas casullas de chamelote; cuatro y cuatro tafetanes con pasamanos de oro y plata y dos bursas de corporales de damasco brocatel ${ }^{66}$.

Además de estas piezas, que fueron tasadas en 1050 ducados y 6 reales, se le encargó a Andrés de Salinas, de acuerdo al mandato de visita, la realización de «... dos corporales de olanda con sus palios de Ruan ${ }^{67}$, doce purificadores con sus cruces al medio, dos albas de lienzo con seis amitos (...) y con las cenefas de la capa negra se aga otra (...) y que la casulla y dalmáticas del terno de oro se reparen...» ${ }^{68}$.

Respecto al trabajo de Andrés de Salinas para Monreal, hay que señalar en primer lugar el lujo e importancia que debieron de tener estas obras, que sobresalen por la riqueza en sus tejidos y en sus bordados. Además vemos como se hace referencia a la decoración, detallándose que esta se haga a lo romano, restringiéndose la imaginería sólo al capillo de la capa. Esto entronca con el panorama general del bordado español, donde la imaginería predomina durante el siglo xvI, sobre todo en su primera mitad, disminuyéndose su uso a finales del mismo siglo y primeros del xvil, cuando empieza a hacerse dominante la decoración a lo romano. Y en último lugar, vemos constatado como se reutilizaban las cenefas de piezas deterioradas aplicándolas a cuerpos nuevos, y como la labor de los bordadores era doble, ocupándose además de ejecutar nuevas obras, de reparar y conservar las ya existentes.

Un año después aparece trabajando para la iglesia de Huarte, llevando a cabo, entre otras obras, una muceta, una casulla de chamelote morado, y dos bursas de corporales, que fueron tasadas por Antonio de Estanga y Juan de Samaniego en 1000 reales, destacando que en la obra había «... damasco, oro y sedas...». Además de esto, Salinas tenía que encargarse de reparar y servir las albas y ornamentos que en la iglesia había, así como dos dalmáticas de chamelote blanco con faldones de chamelote carmesí ${ }^{69}$.

Durante ese mismo año, 1605, aparece ligado a la parroquia de Unzue, para la que hizo una capa de damasco blanco con sus cenefas bordadas y con la insignia de la iglesia, una capa de difuntos de chamelote de aguas también con sus cenefas bordadas, un frontal de damasco

\footnotetext{
${ }^{63}$ Se refiere a la bolsa de corporales, que es una pieza de dos hojas de cartón cuadradas y forradas de tela, entre las cuales se guardan plegados los corporales, que es un lienzo blanco que se extiende sobre el altar, y encima del cual se coloca la Hostia y el Cáliz.

64 A.D. de Pamplona, 1605, C/200-N².

${ }^{65}$ La muceta es una vestidura a modo de esclavina que cubre el pecho y la espalda hasta el codo, abotonada por delante.

${ }^{66}$ El tafetán es una tela de seda, muy tupido pero fino. El brocatel es cierto género de tejido de hierba o cáñamo y seda a modo de brocado.

${ }^{67}$ La holanda es una tela de lienzo muy fina, con la que se solían hacer camisas, y que se llamaba así por ser fabricada en Holanda; y el Ruan es una especie de lienzo fino, llamado así por la ciudad de Ruan, donde se tejía y fabricaba.

68 A.D. de Pamplona, 1606, C/427- $\mathrm{N}^{\circ} 3$.

69 A.D. de Pamplona, 1606, C/427- $\mathrm{N}^{\circ} 18$.
} 
blanco con una figura de Nuestra Señora en medio «... con un cerco muy costoso...», un palio también de damasco blanco «... con sus escudos y calices ... y en medio lleno un sol... y estrellas...»,y cuatro frontales, tres de ellos de lanilla y uno de catalufa ${ }^{70}$. Todo ello fue tasado por los bordadores Martín de Urroz y Juan Rodríguez de Medina en 8181 reales, de los cuáles, aún años después, por el endeudamiento antes aludido en el que se veían inmersas las iglesias, Andrés de Salinas está esperando cobrar una importante parte ${ }^{71}$.

En 1606, ya bajo el obispado de Don Antonio Venegas y Figueroa, lo encontramos trabajando para la parroquia de Echalar. El palaciano de Gaztelu, Don Francés de Gaztelu, había dejado tras su muerte, ochenta ducados para la realización de varios ornamentos para la iglesia de Echalar. Su hermano, Don Martín de Gaztelu, se encarga de que estas obras sean llevadas a cabo, y son solicitadas a Andrés de Salinas, que realizará un frontal de damasco blanco y una muceta de damasco carmesí para el Santísimo Sacramento, por las cuales cobrará, en dos plazos, los dichos ochenta ducados ${ }^{72}$.

En 1609 encontramos a Salinas envuelto en un juicio con el abad de Tirapu, Don Pedro de Goñi, por el asunto de un mantillo de damasco para la imagen de la iglesia, que Salinas había hecho. Fue pagado con diez ducados que el anterior abad dejo tras su muerte para dicho menester. Se acusa a Salinas de haberla hecho demasiado corta, lo que atenta según el abad, contra la decencia. Hay que tener en cuenta que nos hallamos en un ambiente postridentino donde todas las obras de arte deben ir regidas por el decoro. Negábase Salinas a repetirla si no se le pagaba más dinero y el abad le seguía acusando de haber hecho el mantillo corto y de raso falso. Por tal motivo nuestro bordador fue excomulgado, y al final terminó entregando el manto ${ }^{73}$.

A finales del mismo año contrató con la iglesia de Alsasua la realización de un terno con su capa de damasco blanco y un terno de difuntos de lilla con sus calaveras, que debían de ser entregados respectivamente para junio y para Navidad del año siguiente ${ }^{74}$.

Ya en la década siguiente vemos que la actividad profesional de Andrés de Salinas fue abundante. Trabajó, entre otras, para las parroquias de San Martín de Unx, Gazólaz y Berbinzana, realizando para ésta última un terno de terciopelo carmesí y una casulla violada de damasco. También hizo para Muru Astrain diversos ornamentos, que fueron calificados por los tasadores, Juan de Santos y Miguel de Azcárate, como «obras de mucha importancia». Pero sobresalen entre las obras documentadas de esta década, las realizadas para la iglesia de Ollo, para la que realizó una capa y un frontal de damasco blanco bordados, un terno para difuntos, con su capa, casulla y dalmáticas de chamelote negro de aguas, todas bordadas, y cuatro casullas de distintos colores. Las obras fueron tasadas por Martín de Urroz y Miguel de Azcárate en 6593 reales. Se detalla en el contrato que las obras no excedieran en bordadura, especificando que en el terno negro para difuntos «no se haga más bordadura que dos calaberas con sus huesos en cada dalmática y otras dos en la casulla, y en la capa... sendas cruces, no mas de bordado» ${ }^{75}$. Esta medida responde, como estamos viendo, a los intentos de controlar los abundantes gastos que llevaban consigo los ornamentos.

Destaca en la trayectoria profesional de Andrés de Salinas la relación continuada que tuvo con la iglesia de San Vicente de Sada, que demuestra como «la iglesia tenía en los de su valor al dicho Andrés de Salinas» ${ }^{76}$. Realizó para ella una casulla y dos dalmáticas de damasco blanco con cenefas y faldones y demás guarniciones bordadas a lo romano, y con sus figuras bor-

\footnotetext{
${ }_{70}$ Es como un tafetán doble, adornado de flores grandes, de vivos y variados colores.

71 A.D. de Pamplona, 1612, C/242- $\mathrm{N}^{\circ} 28$.

72 A.D. de Pamplona, 1606, C/201- ${ }^{\circ} 2$.

73 A.D. de Pamplona, 1609, C/431- $\mathrm{N}^{\circ} 4$.

74 A.D. de Pamplona, 1620, C/283- $\mathrm{N}^{\circ} 6$.

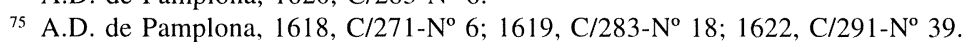

76 A.D. de Pamplona, 1649, C/585- $\mathrm{N}^{\circ} 17$.
}

AEA, LXXVI, 2003, 303, pp. 287 a 300 
dadas de oro y sedas; cuatro frontales de telilla con su cenefas bordadas; dos capas negras, y cuatro bursas con sus tafetanes. Todo ello fue tasado en 1617 por Miguel de Azcárate y Martín de Urroz, en 7.640 reales. En la escritura de convenios de las dichas obras, y más que en principio se contrataron, constaba la obligación de hacerlas «conforme a la traza de la capá blanca que hay en la iglesia», lo cual se explica porque a veces otros ornamentos, que destacaban por sus imágenes y decoración bordada o por su calidad, servían de modelo para las nuevas obras que se llevaban a cabo ${ }^{77}$.

A mediados de la década de los veinte volvió a trabajar para la dicha iglesia, ejecutando una capa de damasco carmesí con capillo y pectoral, y con una imagen del santo titular de la iglesia, San Vicente, en el capillo. La pieza fue tasada en 1628 por Pedro de Unzueta y Pedro de Lecumberri en 311 ducados. Vemos como Andrés de Salinas, nombra como tasador a su yerno, Pedro de Lecumberri, con el fin supuesto de ser favorecido en el valor final de las obras.

Aún, Salinas trabajará otra vez para la iglesia de Sada, llevando a cabo «un frontal de damasco carmesí con sus frontaleras caidas bordadas y uno redondo todo bordado con un San Vicente en medio, un paño de atril de damasco blanco con sus dos faldones bordados y por todas las orillas un requibe bordado, una capa de chamelote de aguas morada con sus cenefas, capillo y pectorales bordados», los cuales fueron estimados por Martín de Urroz y Pedro de Lecumberri, en 7144 reales ${ }^{78}$.

En los últimos años de su vida, su actividad profesional disminuirá, siendo sus trabajos para la iglesia de Sada los últimos documentados. En 1629 nos lo encontramos enfrascado en un pleito contra el bordador Juan González de Ezquerecoechea sobre prioridad de la licencia para realizar varias obras de bordadura para la iglesia de Ustarroz. En él, Juan González de Ezquerecoechea -al que vemos trabajando para distintas iglesias navarras, como Cizur Menor o. Mues - dentro de las descalificaciones mutuas que se profieren, acusa a Salinas de no trabajar hace años y de no tener oficiales a su cargo. Estas afirmaciones hay que verlas dentro del contexto de un litigio en el que los dos quieren hacerse con el contrato de las obras, pero sí hay que tener en cuenta, que tal y como confiesa Andrés de Salinas, él se encontraba enfermo de una pierna, lo cual de una manera u otra debió repercutir en su trabajo, aunque es bien posible, que dejara el trabajo en manos de sus oficiales. Así con todo, lo cierto es que las obras de Ustarroz fueron adjudicadas al otro bordador ${ }^{79}$.

El 20 de abril de 1632 hizo testamento en Pamplona, figurando como testigos Pascual de Estella y Juan de Azpilicueta, dejando a su hijo Juan de Agriano y Salinas como su universal heredero, nombrándolo también su albacea y testamentario. Deja la voluntad de que su cuerpo sea sepultado en «... el claustro de la Catedral en la sepultura que allí tengo...» y que se le hagan entierro y honras «... conforme a la calidad de mi persona...», así como que se le hagan hasta 600 misas rezadas por su alma.

El 14 de julio del mismo año murió Andrés de Salinas, a una avanzada edad y tras una larga enfermedad, siendo enterrado, conforme a su voluntad, «en la iglesia matris desta ciudad» ${ }^{80}$. Se le hicieron un alto número de misas por su alma, en diferentes templos de la ciudad, como el Convento de Nuestra Señora del Carmen «en el altar privilegiado» o en el Convento de Nuestra Señora de la Merced, así como en la misma parroquia de San Juan de la Catedral ${ }^{81}$.

\footnotetext{
77 A.D. de Pamplona, 1633, C7542-N 29; Ágreda Pino, A.M., «Estado de la cuestión, fuentes y metodología para el estudio de los ornamentos de las iglesias zaragozanas (s. XVI)», Artigrama, 10, 1993.

78 A.D. de Pamplona, 1649, C/585-N 17

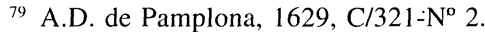

${ }^{80}$ A.D. de Pamplona, Libro de difuntos, San Juan Bautista, Caja 685-2, p. 109.

81 A.D. de Pamplona, 1635, C/540-No 2.
} 
Nos dejó con su muerte, una de las trayectorias profesionales más destacadas del arte del bordado en Navarra. Son muchas las obras que aquí se han enumerado, pero a falta de un trabajo de campo exhaustivo, que esperamos llevar a cabo dentro de poco, es difícil valorar que obras de las citadas se conservan. Lo más probable, debido a la problemática que estas piezas conllevan, tanto por la fragilidad de los materiales que las componen, como por el abandono y olvido de las que han sido objeto, es que las obras conservadas, si existen, sean pocas. Pero siguiendo análisis anteriores, podemos atribuirle como propias dos fragmentos de bordados del siglo XVI que representan a San Lucas y San Juan Evangelista sobre cartelas de cueros retorcidos, que se conservan en la Parroquia de la Asunción de Liedena, así como las cenefas y recuadros que están aplicados a un terno del siglo XIX, en la Iglesia de Santa María de Eguiarte ${ }^{82}$.Según Biurrun y Sotil también son suyas las piezas bordadas de Esparza de Salazar y las obras bordadas de damasco blanco, de la parroquia de Gazólaz ${ }^{83}$.

Pero su trabajo no quedó sólo en él, sino que se dio una continuidad gracias a las obras que tanto su hijo, Juan de Agriano y Salinas, como su yerno, Pedro de Lecumberri, llevaron a cabo. El primero de ellos trabajó, entre otras, para la parroquia de Adiós, para la que realizó varios ornamentos, entre ellos una capa negra y dos casullas; para Orisoain donde ejecutó un conjunto de piezas que fueron tasadas en 126 ducados; y para la iglesia de Lodosa, donde llevó a cabo unas obras, que no pudo acabar ya que la muerte le sorprendió temprano a causa de una enfermedad, y que tuvo que terminar el también bordador Joan de Arratia ${ }^{84}$. En lo que se refiere a sus obras conservadas, se le atribuyen los restos de un terno de difuntos, cuatro casullas y un frontal de San Juan, que se encuentran en la iglesia de San Juan Bautista de Mendavia ${ }^{85}$.

Las obras documentadas que se encuentran del yerno de Salinas, Pedro de Lecumberri, son más que las que hallamos de su hijo. Así, sabemos que trabajó para la parroquia de Monreal, para la que llevó a cabo un terno blanco y para la de Zulueta, donde realizó varios ornamentos que fueron tasados en 2809 reales. Ejecutó también, entre otras piezas, tres frontales de lila para Ucar que fueron tasados en 580 reales; y un terno completo de terciopelo negro para la iglesia de Larraga, que fue estimado en 324 ducados ${ }^{86}$.

Es en consecuencia, Andrés de Salinas, un importante artífice de la aguja, no sólo por las piezas que llevó a cabo, sino también por la prolongación que su trabajo tuvo en las obras de su yerno y de su hijo, así como de los diferentes bordadores que pasaron por su taller. Es además, un hombre de su tiempo, que mantuvo relaciones con los otros bordadores y artistas del momento, estimado por su pericia y buen hacer, y que sobre todo, para Navarra, constituye un ejemplo de cómo pudo desarrollarse esta insigne actividad del bordado en los siglos XVI y XVII.

${ }^{82}$ García Gaínza, Ma C., y otros, Op. cit. Vol. IV**, p. 51; Vol. II**, p. 697,

${ }^{83}$ Biurrun y Sotil, T., Op. cit., p. 466.

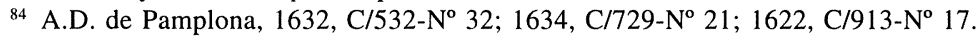

${ }^{85}$ García Gaínza, $\mathrm{M}^{\mathrm{a}}$ C., y otros, Op.cit., Vol. IV**, p. 51.

${ }^{86}$ A.D. de Pamplona, 1617, C/269-N 14; 1618, C/274- $\mathrm{N}^{\circ} 14 ; 1620, \mathrm{C} / 281-\mathrm{N}^{\circ} 2 ; 1630, \mathrm{C} / 711-\mathrm{N}^{\circ} 14$.

$A E A$, LXXVI, 2003, 303, pp. 287 a 300 